\title{
Exploring the Factors Influencing the Strength and Variability of Convectively Coupled Mixed Rossby-Gravity Waves
}

\author{
E. Suhas AND J. M. NeEnA \\ Earth and Climate Science, Indian Institute of Science Education and Research, Pune, Pune, India
}

\author{
XIANAN JIANG \\ Joint Institute for Regional Earth System Science and Engineering, University of California, Los Angeles, Los Angeles, California
}

(Manuscript received 26 March 2020, in final form 14 August 2020)

\begin{abstract}
The three-dimensional structure, horizontal and vertical propagation characteristics, and convectioncirculation coupling of the convectively coupled westward-propagating mixed Rossby-gravity (MRG) waves are examined by classifying the waves based on their amplitude. Convective signals of the MRG waves were identified and isolated using empirical orthogonal function analysis of wavenumber-frequency-filtered outgoing longwave radiation (OLR) data. It was found that about $50 \%$ of the MRG waves occur during the August-November months, and this strong seasonality was considered while characterizing the MRG waves. Five strong and five weak MRG wave seasons were identified during 19792019, based on seasonal wave amplitude, and through this classification, significant differences in the strength of convectioncirculation coupling, zonal scale of circulation, vertical structure, and propagation characteristics of MRG waves were brought out. It was also found that the seasonal mean background state is significantly different during strong and weak MRG wave seasons. While a La Niña-like background state was found to favor enhanced MRG wave activity, the MRG wave activity is mostly suppressed during an El Niño-like background state. The presence of extratropical wave intrusions is another factor that distinguishes the strong MRG wave seasons from the weak ones. Eastward- and northeastwardpropagating extratropical wave trains from the South Atlantic to the east Indian Ocean were observed during strong MRG wave seasons.
\end{abstract}

KEYWORDS: Large-scale motions; Waves, atmospheric; Interannual variability; Tropical variability

\section{Introduction}

The mixed Rossby-gravity (MRG) waves were one of the first category of equatorial waves identified in the lower stratosphere (Yanai and Maruyama 1966; Maruyama and Yanai 1967; Takayabu et al. 2016). They exhibit the characteristics of both Rossby and gravity waves and are defined by a unique dispersion relationship. Though the westward-propagating MRG and the $n=0$ eastward-propagating inertio-gravity (EIG) waves appear continuous in the wavenumber-frequency space, they are dynamically distinct (Takayabu 1994; Wheeler and Kiladis 1999). The MRG waves have received more attention as they influence several other modes of variability (Holton and Lindzen 1972; Takayabu and Nitta 1993; Chen and Huang 2009; Wu et al. 2014; Kiladis et al. 2016; Takasuka et al. 2019). The key features of the MRG waves are the cross-equatorial meridional wind distribution symmetric about the equator and the antisymmetrically distributed quadrupole structure in convection. The MRG wave propagates horizontally and vertically with an approximate phase speed of 20 and $10 \mathrm{~m} \mathrm{~s}^{-1}$, respectively. It has a zonal wavelength ranging from 2000 to $10000 \mathrm{~km}$ and is more active over the equatorial Pacific and the Atlantic (Hendon and Liebmann 1991; Dunkerton and Baldwin 1995; Dunkerton 1993; Takayabu and Nitta 1993; Takayabu 1994; Wheeler and Kiladis 1999; Wheeler et al. 2000; Kiladis et al. 2009, 2016).

Corresponding author: E. Suhas, suhas@iiserpune.ac.in
The easterly momentum transported by the vertically propagating MRG waves through wave-mean flow interactions is known to modulate the quasi-biennial oscillation (QBO), a major mode of variability in the stratosphere (Holton and Lindzen 1972; Plumb 1977). Convectively coupled MRG waves are known to modulate the tropical cyclones, tropical depressions, easterly waves, the Madden-Julian oscillation (MJO), and other tropospheric modes of variability (Dickinson and Molinari 2002; Chen and Huang 2009; Takasuka et al. 2018, 2019).

Since the MRG waves have a dominant rotational wind component, the convectively coupled MRG waves in the lower troposphere play a role in triggering tropical cyclogenesis (Dickinson and Molinari 2002; Chen and Huang 2009; Wu et al. 2014). Several observational studies point to a transition from convectively coupled MRG waves to tropical depressions as the waves propagate from the equatorial central Pacific to the northwest Pacific (Takayabu and Nitta 1993; Chen and Huang 2009; Wu et al. 2014; Zhao et al. 2019). The state of the zonal mean background flow and energy conversions between the mean flow and the synopticscale waves are considered crucial for aiding such transitions (Sobel and Bretherton 1999; Wu et al. 2014; Feng et al. 2016). Thus, the convectively coupled MRG waves enable scale interactions among different modes of tropical variability.

Several studies (Takayabu 1994; Wheeler and Kiladis 1999; Wheeler et al. 2000; Roundy and Frank 2004; Hendon and Wheeler 2008; Kiladis et al. 2009) have helped us understand the spatial and temporal structure and propagation characteristics of convectively coupled MRG waves and helped identify the 
domain of activity. Nevertheless, there are still several unanswered questions pertaining to the characteristics of the waves (for brevity, hereafter we refer to convectively coupled MRG waves simply as MRG waves). For example, the interannual variability of MRG waves and the factors influencing such variability have not been rigorously examined using a long record of data. While several past studies have examined the seasonality of MRG waves (Hendon and Liebmann 1991; Takayabu and Nitta 1993; Magaña and Yanai 1995; Wheeler et al. 2000; Roundy and Frank 2004; Kiladis et al. 2016), most of them were based on data of limited size, and the MRG wave active season varied among the different studies. Hendon and Liebmann (1991) identifies the October-November months as the MRG dominant season, while others (Takayabu and Nitta 1993; Wheeler et al. 2000) mark the June-August months or a broader May-October period (Magaña and Yanai 1995; Au-Yeung and Tam 2018) as the MRG wave active season. While reviewing some of the recent studies on MRG waves we found that the free and convectively coupled MRG waves were not separated in most of these studies. Also, the statistics presented in some of the studies were based on sampling the MRG wave activity during boreal winter season, which might not be an optimal strategy if the waves followed a different seasonal cycle.

A proper identification of the MRG season is crucial for documenting and attributing the role of these waves in modulating the other modes of tropical variability. The possible dependence of convectively coupled MRG wave activity on the mean state is also not well understood. While some studies suggest that the distribution of sea surface temperature in the central Pacific play a major role in exciting the convectively coupled MRG waves (Hendon and Liebmann 1991), others emphasize on the contribution of extratropical wave intrusions (Mak 1969; Itoh and Ghil 1988; Magaña and Yanai 1995; Yang and Hoskins 2016). Takayabu and Nitta (1993) noted that MRG wave activity increases during La Niña conditions. However, a recent study by $\mathrm{Wu}$ et al. (2014) found no relationship between El Niño-Southern Oscillation (ENSO) phase and MRG wave activity. The differences in the seasonality reported for the MRG waves, the dependence on relatively small sample size in deriving the statistics, and the different approaches used for identifying the MRG wave activity motivate us to reexamine the issue using a more objective method and a longer record of data that can account for the changes in the different large-scale factors. Addressing these questions is also important for improving our understanding of not only the convectively coupled MRG waves but also the interaction between the large-scale and the convective-scale motions in the tropics.

Therefore, in the current study we aim to address these issues by performing a detailed analysis of the convectively coupled MRG waves. The strategy adopted in the present study is to segregate the observed MRG waves into strong and weak amplitude classes and examine their characteristics separately. The role of background state that influence the strength of MRG wave activity, and the role of extratropical waves in triggering the MRG waves are also explored. Section 2 provides the details of the data and methodology adopted. Section 3 discusses the results, and section 4 summarizes and concludes the study.

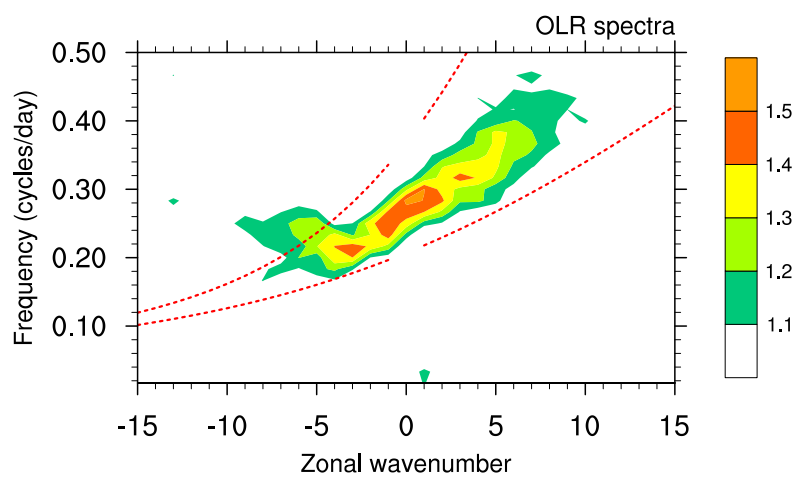

FIG. 1. The antisymmetric wavenumber-frequency power spectra of OLR for the 1979-2019 period, normalized by the smooth red background. The normalized power greater than 1.1 is statistically significant above the background at $95 \%$ confidence level. The red dashed lines represent the dispersion curves of shallow-water MRG and $n=0$ eastward-propagating inertio-gravity waves of equivalent depth 10 and $100 \mathrm{~m}$.

\section{Data and methodology}

To identify the convective signal of the MRG waves we used the NOAA interpolated daily outgoing longwave radiation (OLR) data from 1 January 1979 to 31 December 2019 (Liebmann and Smith 1996). Horizontal wind components, and geopotential height data from ERA-Interim reanalysis for the same period at daily resolution with a horizontal resolution $2.5^{\circ}$ from 1000 to $50 \mathrm{hPa}$ pressure levels were used for extracting the horizontal and vertical structures of convectively coupled MRG waves (Dee et al. 2011). We have used monthly sea surface temperature (SST) of NOAA_OI_SST_V2 data provided by the NOAA/OAR/ESRL Physical Sciences Laboratory (PSD) in Boulder, Colorado (https://www.esrl.noaa.gov/psd/; Reynolds et al. 2002).

Wavenumber-frequency power spectral analysis (Wheeler and Kiladis 1999) was used for identifying the MRG waves in convection. The antisymmetric spectra normalized by the smooth red background clearly shows the presence of the MRG waves (Fig. 1). As noted by many previous studies, a significant portion of the MRG power lies between the equivalent depths of 10 and $100 \mathrm{~m}$ (Wheeler and Kiladis 1999; Wheeler et al. 2000; Kiladis et al. 2009). Though the MRG and $n=0$ EIG waves variances appear continuous across positive and negative zonal wavenumbers, we will focus only on the westward-propagating MRG waves, since it is known to have a relatively larger influence on the various modes of tropical variability (Holton and Lindzen 1972; Dickinson and Molinari 2002; Lin et al. 2019; Zhao et al. 2019). The maximum spectral power corresponding to the westward-propagating MRG waves is centered around wavenumber 3 with a period of 4.5 days. To isolate the convectively coupled MRG waves we adopt an approach that combines wavenumber-frequency filtering and empirical orthogonal function (EOF) analysis. First, the MRG wave power was filtered out from daily OLR data for wavenumbers -10 to -2 and period 3-6 days. To bring out the dominant structures of MRG variability, an EOF analysis was carried out using the wavenumber-frequency filtered daily 

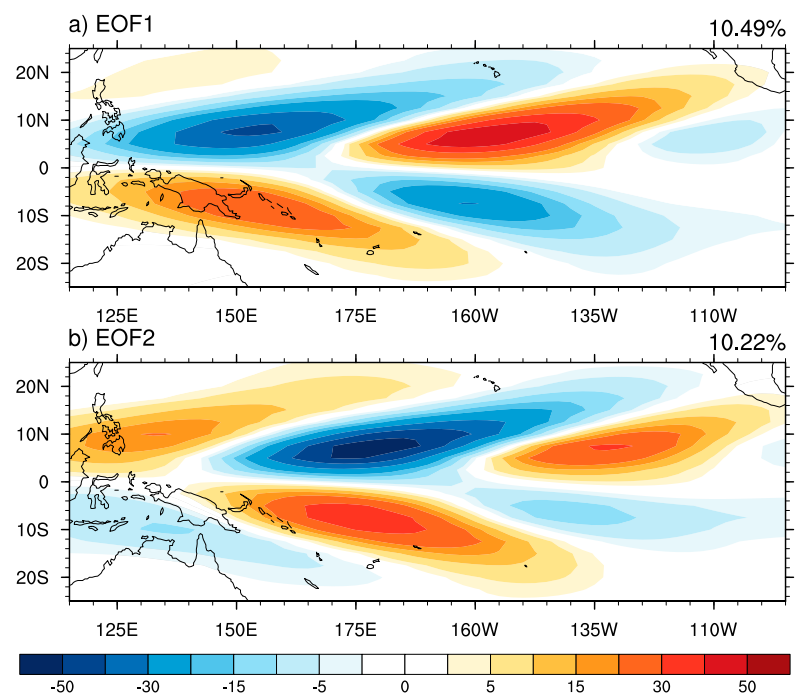

FIG. 2. First two leading modes of the EOF analysis of wavenumberfrequency-filtered westward-propagating MRG waves in OLR over the tropical Pacific domain $\left(25^{\circ} \mathrm{S}-25^{\circ} \mathrm{N}, 110^{\circ} \mathrm{E}-95^{\circ} \mathrm{W}\right)$. Units are arbitrary. Percentage of variance explained by the EOF modes is shown at the top-right corner of each panel.

OLR field over the tropics $\left(25^{\circ} \mathrm{S}\right.$ to $\left.25^{\circ} \mathrm{N}\right)$. A recent study by Roundy (2015) advises exercising caution while applying EOF analysis to isolate equatorial waves, as neglecting higher EOF modes might ignore smaller-scale waves, which might in turn lead to an incomplete characterization of the waves. EOF analysis of MRG filtered OLR reveals that the first eight EOF modes occur in pairs and only the first two pairs are well separated from the higher modes (North et al. 1982). The higher EOF modes (EOF modes 3 to 8 ) capture the smaller-scale MRG waves and together they explain about $13 \%$ of the MRG variability. However, the amplitude of the smaller-scale MRG waves isolated using the higher EOF modes were found to be not significant and the convection-circulation structure derived from these higher EOF modes did not conform to the MRG wave structure. Hence, the higher EOF modes were not considered in the analysis.

The leading EOF modes indicate that the MRG waves in convection is limited only to the tropical Pacific region. To improve the signal-to-noise ratio, we restricted the domain of analyses to the tropical Pacific region $\left(25^{\circ} \mathrm{S}-25^{\circ} \mathrm{N}, 110^{\circ} \mathrm{E}-\right.$ $\left.95^{\circ} \mathrm{W}\right)$. The first two EOF modes of the MRG waves over tropical Pacific, together explain more than $20 \%$ of the total variability (Fig. 2). It is clear from Fig. 2 that these two leading EOF modes capture the westward-propagating phases of the quadrupole structure of the same MRG mode in convection. The first EOF mode represents the Northern Hemispheric MRG convective phase east of the date line and the second EOF mode represents the Northern Hemispheric MRG convective phase centered around the date line. We chose the principal component (PC) corresponding to the second EOF mode as the MRG wave index (the overall results of the study are not sensitive to this choice). The horizontal structure of the MRG wave is brought out by correlating unfiltered daily anomalies of OLR, and lower $(800 \mathrm{hPa})$ and upper-tropospheric
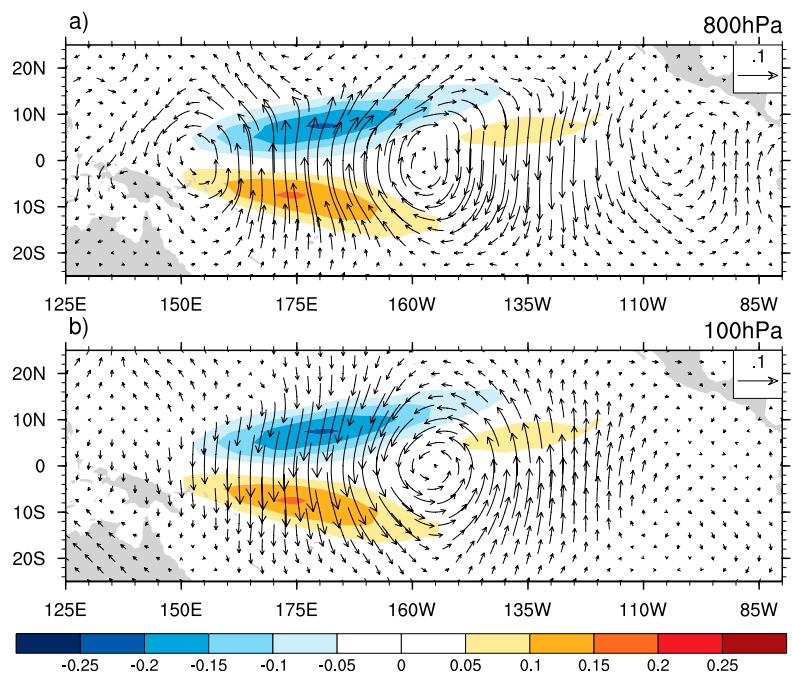

FIG. 3. The horizontal structure of the MRG waves in OLR (shading) and zonal wind anomalies (vectors) at (a) 800 and (b) $100 \mathrm{hPa}$. It is extracted by correlating the daily MRG wave index with the OLR and wind anomalies at the two pressure levels during the 1979-2019 period.

$(100 \mathrm{hPa})$ zonal and meridional winds against the MRG wave index (Fig. 3). The daily anomalies are calculated by subtracting the daily climatology from the respective fields. The horizontal structure of the MRG waves, including the quadrupole structure in convection, and cross-equatorial meridional wind anomalies near the date line are captured in Fig. 3 and is quite similar to the theoretical structure of MRG wave (Matsuno 1966). It is evident from Fig. 3 that the MRG waves have a significant projection in the lower- and upper-tropospheric circulation. The MRG waves in the upper-tropospheric circulation have a larger zonal scale and is phase shifted with respect to the structure in the lower troposphere. The time evolution of the horizontal and vertical structure of the convectively coupled MRG waves were extracted by correlating the MRG wave index against convection and circulation anomalies at different time lags. Since the MRG waves exhibit a peak periodicity around 5 days, we examined the zonal and vertical propagation characteristics of the wave disturbances from 2-day lag to 2-day lead times.

\section{Results and discussion}

\section{a. Identification of strong and weak MRG seasons}

The seasonality of MRG waves have been explored by several past studies (Hendon and Liebmann 1991; Takayabu and Nitta 1993; Magaña and Yanai 1995; Wheeler et al. 2000; Roundy and Frank 2004; Kiladis et al. 2016; Au-Yeung and Tam 2018). Some of these studies identify October-November months as the MRG dominant season, while others mark the June-August months as the MRG season (Hendon and Liebmann 1991; Takayabu and Nitta 1993; Roundy and Frank 2004). On the other hand, studies like Magaña and Yanai (1995), Au-Yeung and Tam (2018), and others using meridional-windbased isolation of MRG waves identify the boreal summer and fall (May-October months) as the MRG wave active season. The 
MRG waves in a significant fraction of these studies were identified based on a reference time series near the equatorial central Pacific (Hendon and Liebmann 1991; Magaña and Yanai 1995; Wheeler et al. 2000; Kiladis et al. 2009). Since the waves are dynamic entities and the geographical occurrences of the wave disturbances might be influenced by different large-scale factors, the inferences made based on a time series restricted to a fixed geographical location might not be sufficient to derive the whole picture. Another factor that encouraged us to revisit the MRG seasonality issue was the fact that our current understanding of the waves is based on earlier studies that relied on data of relatively small sample size. In this study, we use an EOF-based methodology to objectively derive an MRG wave index for 41 years, using which we reexamined the seasonality of MRG waves and explored its characteristics. Periods of strong MRG activity were identified as when the normalized MRG wave index exceeded unity. For each calendar month, the frequency of occurrence of such strong MRG wave activity was examined for the period 1979-2019. The analysis indicates a high probability of occurrence (about $50 \%$ ) of MRG wave activity during late boreal summer and fall (Fig. 4a), suggesting a strong seasonality associated with the convectively coupled MRG waves. This observation is different from the previous studies and this finding is crucial for analyzing the sensitivity of MRG wave activity to different background states and its influence on different weather and climate phenomena. For example, a recent study by Yang and Hoskins (2016) examined the dependence of MRG wave activity on the ENSO by restricting the analysis to November-April months. But our finding indicates that Yang and Hoskins (2016) might have missed most of the strong MRG wave activity during late boreal summer and fall. Therefore, for further analysis we focus on the late summer to fall season (August-November), which we define as the MRG wave season.

The interannual variability of MRG wave activity during the August-November MRG wave season was further examined. The variance of daily MRG wave index during the AugustNovember period every year was used to define the MRG seasonal amplitude. Five strong and five weak MRG seasons were identified from the MRG seasonal wave amplitudes from 1979 to 2019 (Fig. 4b, Table 1). Further analysis showed that strong MRG wave seasons consist of a greater number of MRG wave events and the average amplitude of the MRG wave events during each season was significantly larger than that for weak MRG wave seasons (Table 1). The spatial distribution of wavenumber-frequency (MRG) filtered OLR variance for the five strong seasons, five weak seasons, and all other seasons with moderate amplitude are shown in Fig. 5. The larger MRG variance observed during strong seasons and weaker variance observed during weak seasons justifies the method used for identifying MRG wave activity. Interestingly, the domain of MRG activity is also different during strong and weak seasons, affirming the advantage of using an EOF-based dynamic MRG index. For example, during strong MRG seasons, dominant MRG activity is observed in the off-equatorial region west of the date line, whereas during weak MRG seasons the domain of activity is observed over the western Pacific centered around $130^{\circ} \mathrm{E}$. The wavenumber-frequency spectra of OLR for strong MRG seasons show the distribution of spectral power over a
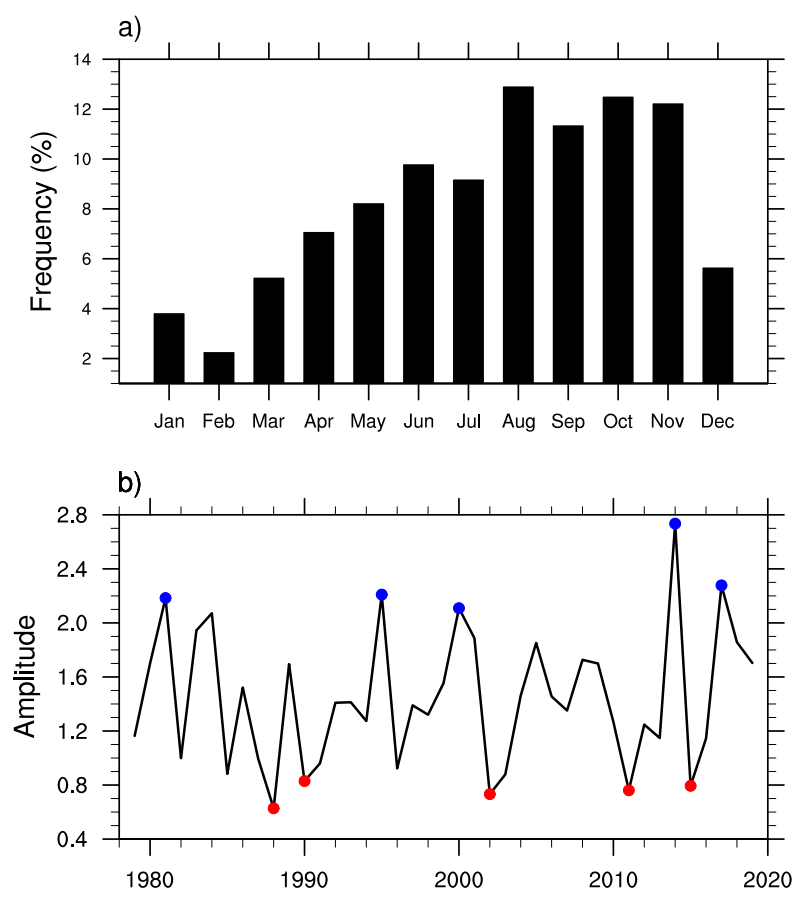

FIG. 4. (a) Monthly distribution of the frequency of occurrence of MRG wave activity in convection during the 1979-2019 period, expressed as a percentage with respect to the total number of events. An MRG wave activity is identified as when the normalized daily MRG wave index exceeded one standard deviation. (b) Seasonal amplitude of the MRG wave activity for the 1979-2019 period. Seasonal amplitude of the MRG waves was estimated as the variance of the daily MRG wave index for the August-November months each year. Blue dots represent the five strong MRG wave seasons, and red dots represent five weak MRG seasons.

broad wavenumber range from -10 to -2 and period $3-6$ days, with maximum power corresponding to wavenumber -4 at a periodicity of 4.5 days (Fig. 6a). A shift in peak power is observed in the spectra for weak MRG seasons, with maximum power observed at a relatively shorter frequency (wavenumber -7 , frequency $=0.2$ cycles per day) (Fig. 6b). The antisymmetric coherence spectra between OLR and zonal wind anomalies at $850 \mathrm{hPa}$ performed separately for strong and weak MRG seasons also agree with the previous analysis results (Figs. 6c,d). The stronger coherence observed between OLR and zonal wind at wavenumber -5 to -2 during strong MRG seasons implies a stronger coupling between convection and circulation (Hendon and Wheeler 2008). Interestingly, for the weak MRG wave seasons, significant convection-circulation coupling is observed only for the $n=0$ EIG waves. From the variance and spectral analysis, it can be inferred that the strong and weak MRG season classification is physical and both groups exhibit dynamically distinct features.

\section{b. Horizontal and vertical structure of the MRG waves during strong and weak seasons}

The horizontal structure of convectively coupled MRG waves in convection and lower- (Fig. 7) and uppertropospheric (Fig. 8) circulation fields were extracted by correlating the MRG wave index with unfiltered OLR and wind 
TABLE 1. Five strong and five weak MRG wave seasons identified based on the MRG seasonal wave amplitudes from 1979 to 2019 . The total number of MRG events during the season and the average amplitude of MRG wave events during the season are also shown.

\begin{tabular}{lcc}
\hline \hline Strong MRG wave seasons & Number of MRG wave events & Average amplitude of MRG wave events \\
\hline 1981 & 17 & 2.22 \\
1995 & 17 & 2.34 \\
2000 & 18 & 1.87 \\
2014 & 21 & 2.31 \\
2017 & 22 & 2.09 \\
Weak MRG wave seasons & Number of MRG wave events & Average amplitude of MRG wave events \\
1988 & 9 & 1.37 \\
1990 & 8 & 1.71 \\
2002 & 7 & 1.5 \\
2011 & 9 & 1.65 \\
2015 & 10 & 1.64 \\
\hline
\end{tabular}

anomalies at 800 and $100 \mathrm{hPa}$ pressure levels, respectively. Since the MRG waves exhibit a periodicity of 3-6 days, a -2 to +2 day lag correlation approach was used to capture its time evolution. Salient features of the convectively coupled MRG waves are visible during both strong and weak seasons. The MRG waves exhibit a baroclinic structure in circulation with anticyclonic circulation in the lower level accompanied by cyclonic circulation at $100 \mathrm{hPa}$ and vice versa (Figs. 7 and 8). The correlation maps representing the structure of the MRG waves in the relative vorticity field at $100 \mathrm{hPa}$ (Fig. 8, shading), brings out a symmetric structure about the equator. For the strong MRG seasons, it is quite evident that the wave structure in the upper-tropospheric circulation has a larger zonal scale compared to that in the lower-tropospheric circulation. And, consistent with the wavenumber-frequency coherence spectra (Figs. 6c,d), the zonal scale in lower-level circulation during weak seasons appears to be smaller than that during strong seasons. However, it is not possible to validate the statistical robustness of the difference in zonal scale, as the MRG wave structure is too weak during weak MRG seasons. The lag-lead correlation maps from Figs. 7 and 8 were also examined to understand the phase propagation of the waves during strong and weak seasons (Fig. 9). The correlation coefficients of the MRG wave index with the OLR anomalies were latitudinally averaged over $5^{\circ}-10^{\circ} \mathrm{N}$ and those with the 800 and $100 \mathrm{hPa}$ meridional wind anomalies were averaged over $2.5^{\circ} \mathrm{S}-2.5^{\circ} \mathrm{N}$ latitudes. A clear westward phase propagation is observed from the central Pacific to the western Pacific. However, noticeable differences are evident in the horizontal phase speed of the MRG waves during strong and weak seasons. During strong seasons, the waves exhibits a convective phase speed of $\sim 23 \mathrm{~m} \mathrm{~s}^{-1}$, and a phase speed of $\sim 19 \mathrm{~m} \mathrm{~s}^{-1}$ in the lower- and

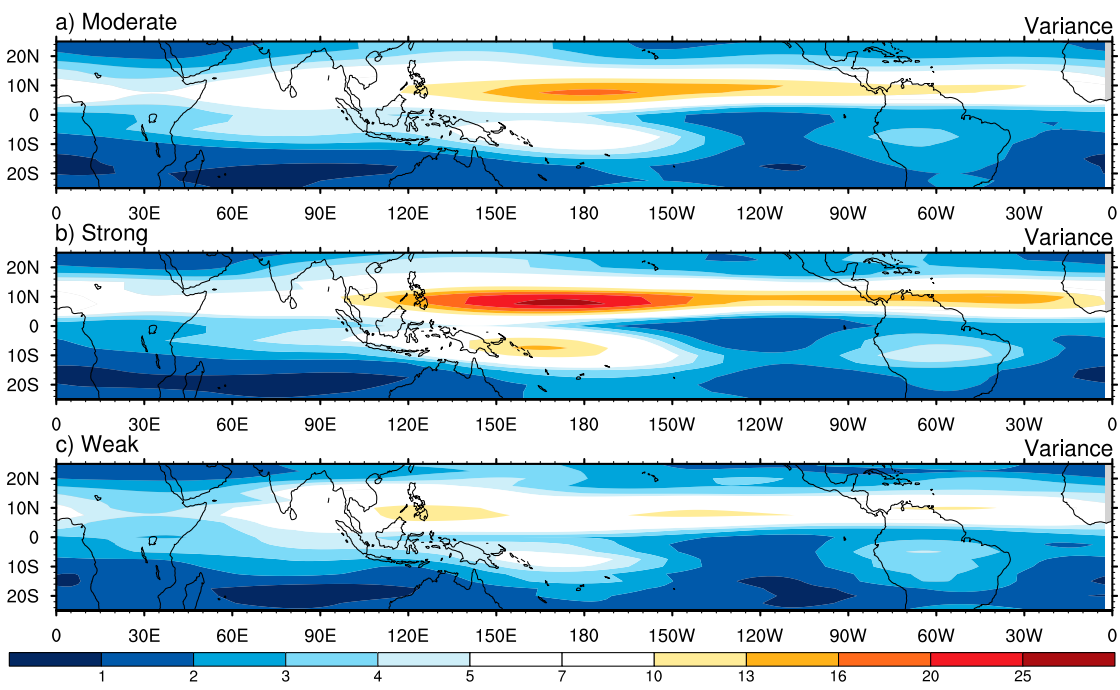

FIG. 5. MRG wave variance of wavenumber-frequency filtered daily OLR anomalies $\left(\mathrm{W}^{2} \mathrm{~m}^{-4}\right.$ ) for (a) moderate MRG wave seasons (all other MRG wave seasons excluding the strong and weak seasons), (b) strong MRG wave seasons, and (c) weak MRG wave seasons. 

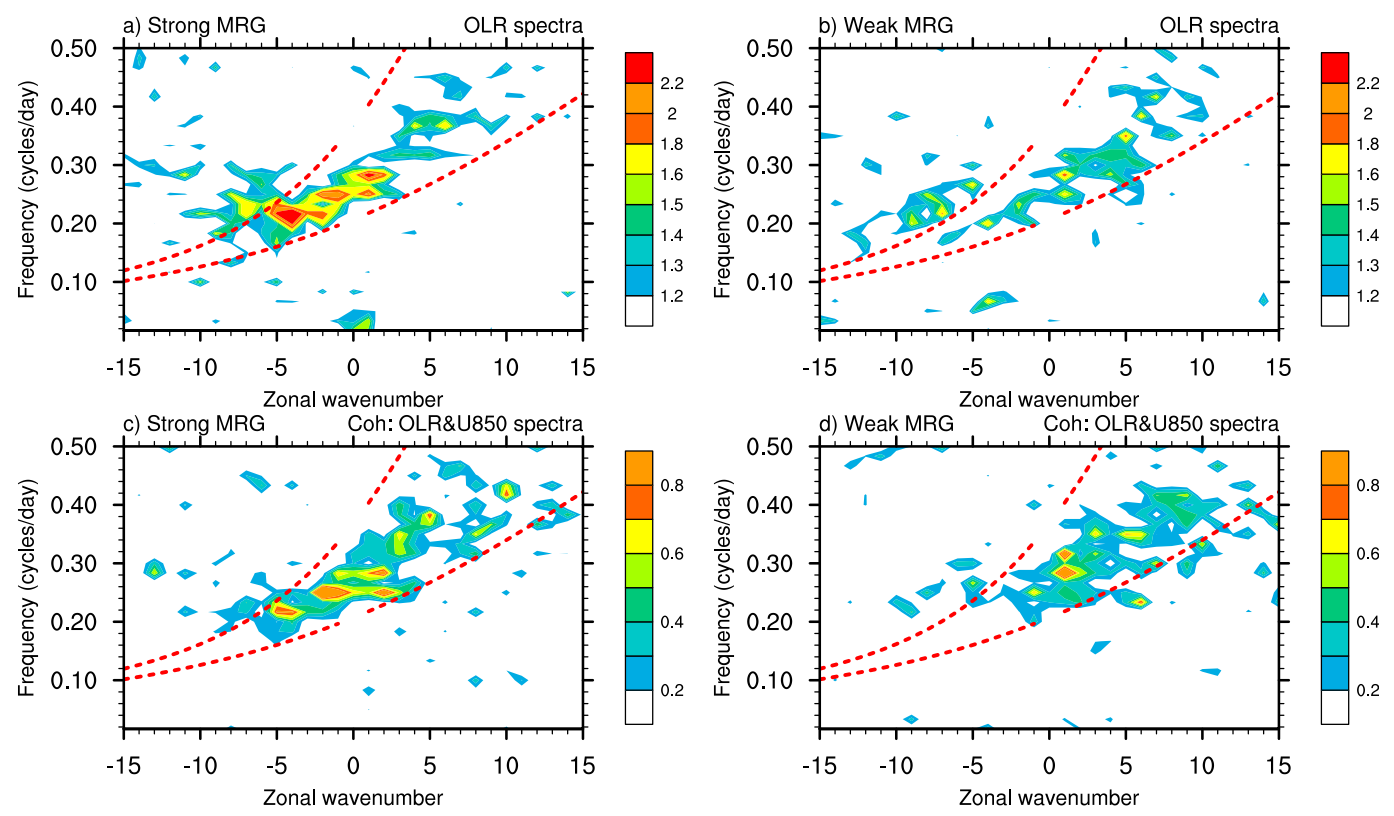

FIG. 6. (a),(b) The antisymmetric red-background normalized wavenumber-frequency spectra of OLR for strong and weak MRG wave seasons. (c),(d) Wavenumber-frequency coherence-squared spectra between OLR and $850 \mathrm{hPa}$ zonal wind anomalies for strong and weak MRG wave seasons. The red dashed lines represent the dispersion curves of the shallow-water MRG and $n=0$ EIG waves of equivalent depth 10 and $100 \mathrm{~m}$.

upper-level circulation. While the phase speed of the waves in convection is greater than that in circulation during both seasons, a relatively higher phase speed is observed in convection $\left(\sim 34 \mathrm{~m} \mathrm{~s}^{-1}\right)$ and upper-level circulation $\left(\sim 33 \mathrm{~m} \mathrm{~s}^{-1}\right)$ during weak MRG seasons. The observation of faster phase speed of MRG waves during weak MRG seasons corroborates the inference derived from the wavenumber-frequency coherence spectra that the MRG waves during weak MRG seasons are weakly convectively coupled.

The observed differences in the horizontal scale and position of the MRG waves at $100 \mathrm{hPa}$, could be the result of Doppler shifting due to the presence of stronger background flow and wave absorption by the critical layer. The observed tilt in the vertical structure of the convectively coupled MRG waves in circulation also indicates the possibility of vertical transport of horizontal momentum from troposphere to stratosphere (Yanai et al. 1968; Kiladis et al. 2009). This aspect was further explored by examining the vertical structure of the MRG waves from the lower troposphere to the lower stratosphere. Figure 10 shows the vertical structure of the MRG waves in zonal winds during strong and weak seasons brought out by lag correlating the MRG wave index with the antisymmetrically averaged zonal wind anomalies at $7.5^{\circ} \mathrm{N}$ from 1000 to $50 \mathrm{hPa}$ pressure levels. Antisymmetrically averaged zonal wind anomalies were used since the MRG waves in zonal wind show an antisymmetric distribution about the equator with maximum amplitude around $7.5^{\circ} \mathrm{N}$, while the meridional wind structure is symmetric about the equator (Matsuno 1966; Wheeler and Kiladis 1999). The symmetric and antisymmetric components of circulation were brought out by following the approach introduced by Yanai and Murakami (1970).
The MRG waves' vertical structure exhibits an eastward tilt with height from the lower troposphere to the upper troposphere (1000-200 hPa) and a westward tilt from the upper troposphere to the lower stratosphere. The vertical tilt indicates the direction of MRG group velocity. The west-east orientation of tilt in the lower troposphere implies downward group velocity and the east-west orientation of tilt in the stratosphere implies upward group velocity (Yanai et al. 1968). The orientation of vertical tilt has important dynamical bearings on the momentum transport between the troposphere and the stratosphere. During strong MRG seasons the vertically tilted easterly and westerly wind anomalies propagate westward from the east Pacific to the west Pacific (Figs. 10a-e). On the other hand, during weak seasons, the MRG waves exhibit only a weak vertical structure in zonal winds (Figs. 10f-j). Since the tilt in vertical structure of a wave is indicative of vertical momentum transport, the existence of weak vertical tilt in the troposphere implies weak zonal momentum transport from the lower to the upper troposphere by the MRG waves. Figure 11 shows the vertical structure of MRG waves in meridional winds, brought out by correlating the MRG wave index with the symmetrically averaged meridional wind anomalies at the equator. The west-east-oriented vertical tilt in the troposphere and eastwest-oriented vertical tilt in the upper troposphere and stratosphere is more evident in the meridional wind structure. Consistent with the linear equatorial wave theory, the MRG wave vertical structure is more prominent in meridional winds during both strong and weak seasons. Nevertheless, the meridional wind structure is weaker during weak MRG seasons.

The vertical phase propagation of MRG waves during strong and weak seasons was examined by correlating the relative 

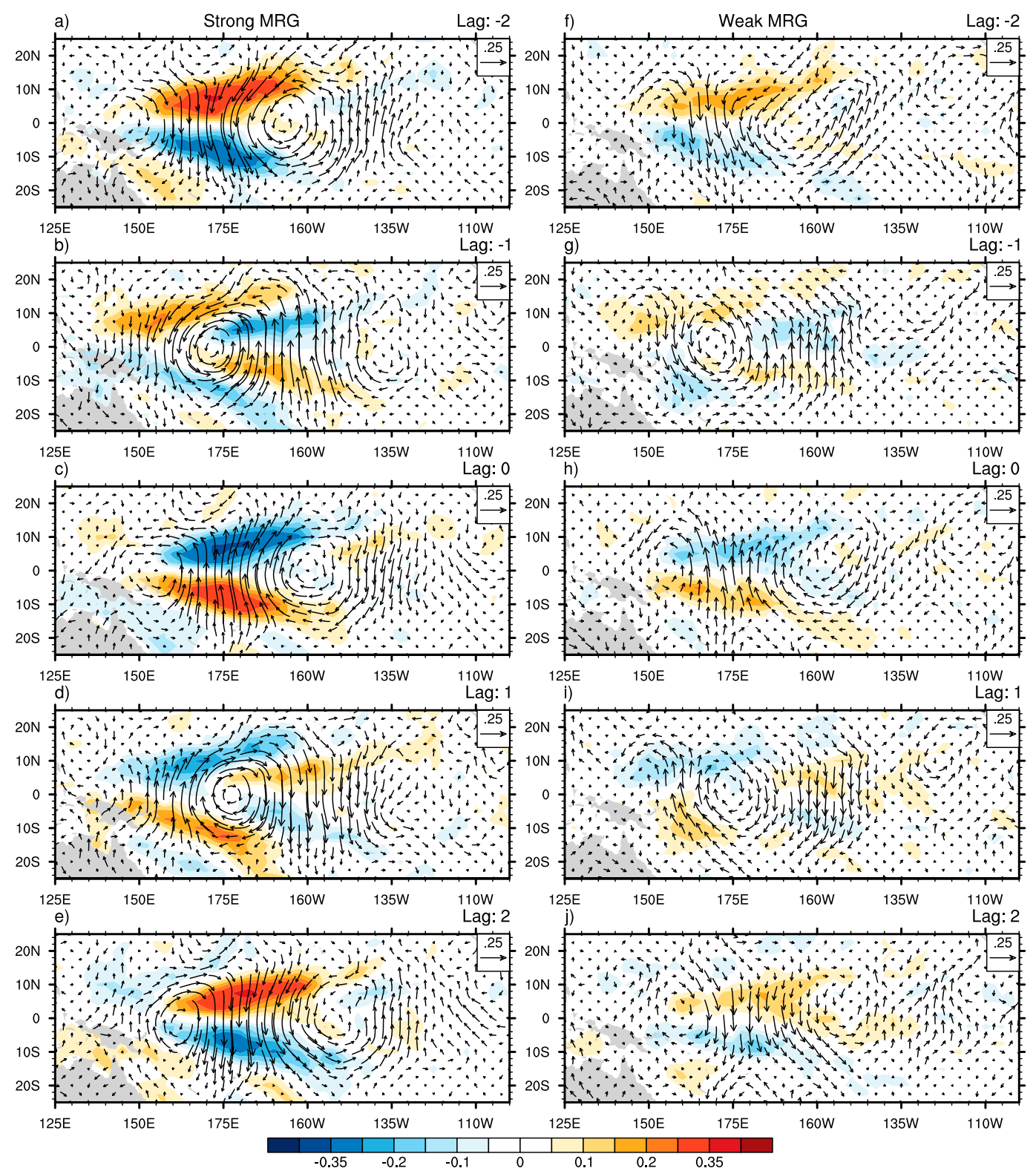

FIG. 7. Spatial correlation of the OLR (shading) and $800 \mathrm{hPa}$ wind (vectors) anomalies with the MRG wave index from 2-day lag to 2-day lead times during (a)-(e) strong MRG wave seasons and (f)-(j) weak MRG wave seasons. A positive lag value indicates that the MRG wave index leads the OLR and wind anomalies.

vorticity anomalies at different pressure levels with the MRG wave index, at different time lags. The lead-lag correlation coefficients west $\left(0^{\circ}, 167.5^{\circ} \mathrm{E}\right)$ and east $\left(0^{\circ}, 167.5^{\circ} \mathrm{W}\right)$ of the date line are shown in Fig. 12. MRG waves during strong seasons indicate an upward phase propagation from the lower troposphere to the upper troposphere and a downward phase propagation from the stratosphere to the upper troposphere. On the other hand, the group velocity as interpreted from Figs. 10 and 11 was directed downward in the troposphere and upward in the stratosphere. Since the energy propagates in the direction of group velocity, upward propagation of group velocity in the stratosphere implies the role of tropical convection in exciting vertically propagating waves from the upper troposphere to the stratosphere. The MRG waves in relative vorticity, west (Fig. 12a) and east (Fig. 12c) of the date line show consistent vertical propagation characteristics during strong MRG seasons. However, the MRG waves during weak seasons are weak and do not show a clear vertical propagation in the upper troposphere. It appears that the MRG waves vertical propagation during weak seasons becomes discontinuous near $500 \mathrm{hPa}$ west of the date line (Fig. 12b) and around $400 \mathrm{hPa}$ east of the date line (Fig. 12c). In short, the horizontal momentum transport by the convectively coupled MRG waves from the troposphere to the 

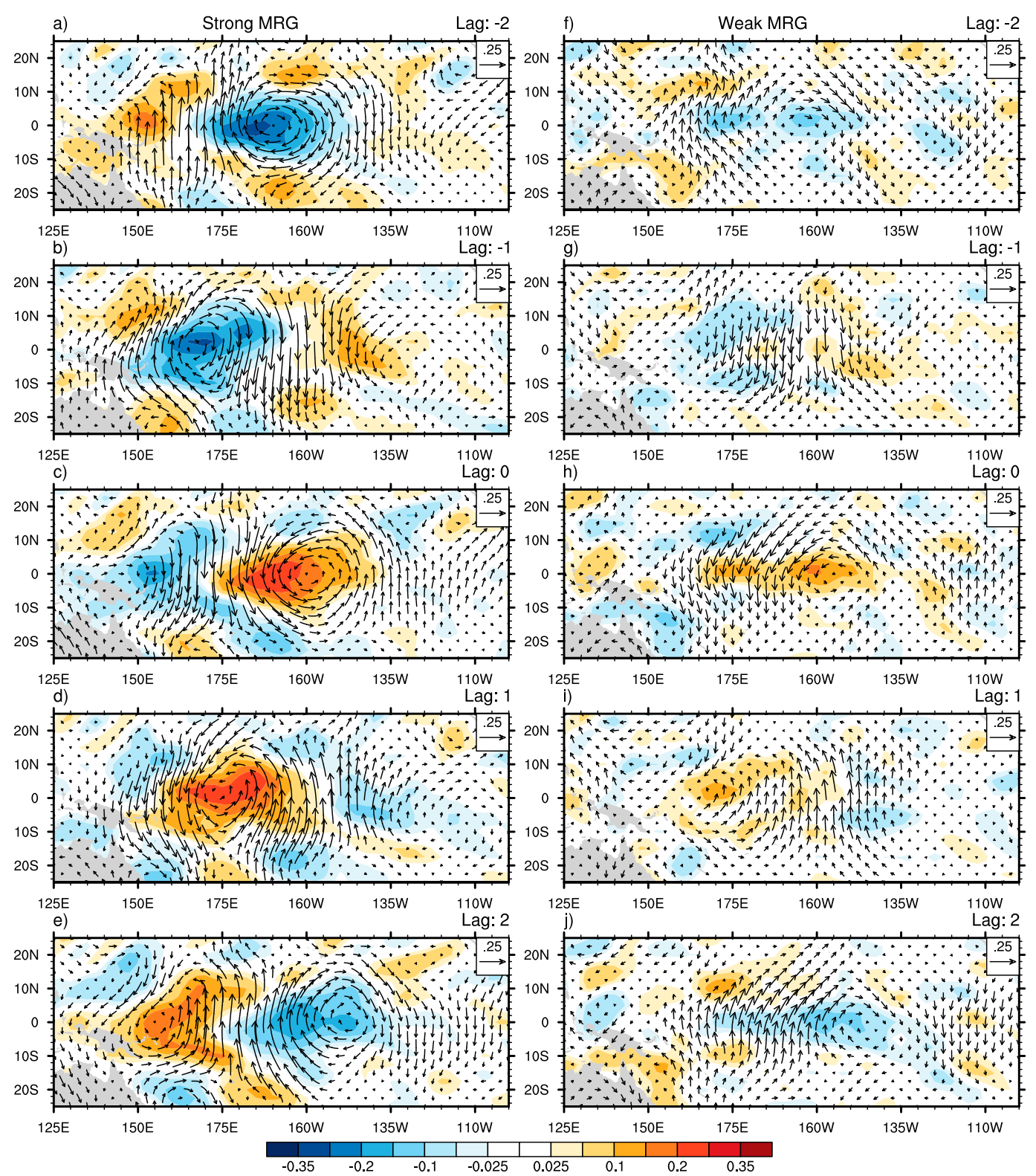

FIG. 8. Spatial correlation of the relative vorticity (shading) and wind (vectors) anomalies at $100 \mathrm{hPa}$ with the MRG wave index from 2-day lag to 2-day lead times during (a)-(e) strong MRG wave seasons and (f)-(j) weak MRG wave seasons. A positive lag value indicates that the MRG wave index leads the relative vorticity and wind anomalies.

stratosphere seems to be feasible only during strong MRG wave seasons.

\section{c. Large-scale factors influencing the strong and weak $M R G$ seasons}

\section{1) Mean Background State}

Many previous studies have explored the sensitivity of the equatorial waves to the background state (Wang and Xie 1996; Wang 2006; Wu et al. 2014; Yang and Hoskins 2016). It has been reported that the seasonal mean background flow can modulate the spatial and temporal structures and energetics of synoptic-scale waves, including MRG waves, through wavemean flow interactions and available potential energy-kinetic energy conversions (Lau and Lau 1990; Wu et al. 2014; Feng et al. 2016; Au-Yeung and Tam 2018). To understand the influence of background state on the observed differences in the MRG wave characteristics during strong and weak seasons, we examined the seasonal mean circulation and convective state during strong and weak MRG seasons. Seasonal mean composites of OLR, SST, and wind anomalies at 800 and $100 \mathrm{hPa}$ for strong and weak MRG seasons are shown in Fig. 13. It 

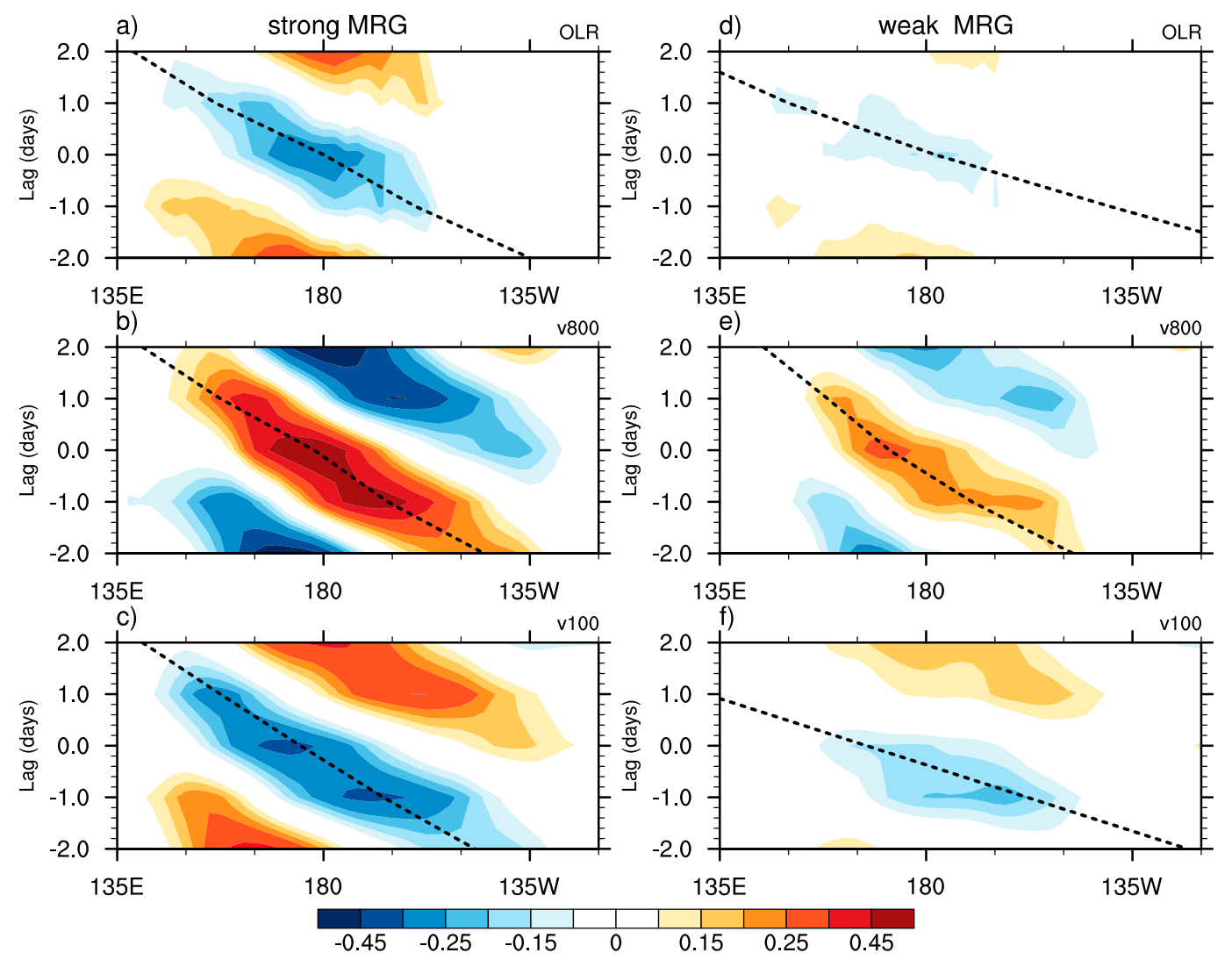

FIG. 9. Phase propagation of MRG waves in (top) OLR, (middle) $800 \mathrm{hPa}$ meridional wind component, and (bottom) $100 \mathrm{hPa}$ meridional wind component during (a)-(c) strong MRG wave seasons and (d)-(f) weak MRG wave seasons. The composite MRG phase propagation in OLR was estimated by averaging the lead-lag correlation maps between OLR and MRG wave index (Fig. 7) over latitudes $5^{\circ}-10^{\circ} \mathrm{N}$. The composite MRG phase propagation in lower- and upper-tropospheric meridional winds were estimated by averaging the corresponding lead-lag correlation maps (Figs. 7 and 8 ) over latitudes $2.5^{\circ} \mathrm{S}-2.5^{\circ} \mathrm{N}$. The black dashed lines indicate the phase speed of the MRG waves.

is interesting to note that the seasonal mean states are significantly different during strong and weak MRG seasons. During strong MRG seasons, the seasonal mean state over the equatorial Pacific resembles a La Niña-like background state where the dominant convective activity is over the western Pacific with easterly wind anomalies in the lower troposphere and westerly wind anomalies in the upper troposphere. On the other hand, weak MRG seasons are characterized by an El Niño-like background state with the convection and circulation structure exhibiting opposite characteristics. Putting together the observed differences in the background state and the phase speed of MRG waves during strong and weak seasons (Figs. 9c,d), we suspect that the higher phase speed of the MRG waves during weak seasons might be attributed to the Doppler shifting by strong upper-level easterlies. This finding brings in a new perspective, as an earlier study (Wu et al. 2014), which examined the amplitude dependence of MRG waves on the different phases of ENSO, could not identify any significant difference in MRG amplitude during El Niño or La Niña. While the composite analysis discussed above, is not sufficient to bring out the cause-effect relationship between the strength of convectively coupled MRG waves and the background state, it clearly indicates the existence of a strong coupling between the MRG wave activity and the equatorial Pacific background state. The role of the background state in determining the amplitude and scale selection of MRG waves needs to be examined more thoroughly.

\section{2) EXTRATROPICAL FORCING}

Extratropical forcing is considered to play an important role in exciting the MRG waves in the tropics (Mak 1969; Hayashi and Golder 1978; Itoh and Ghil 1988; Magaña and Yanai 1995; Yang and Hoskins 2016). We examined whether there is any noticeable difference in terms of the presence or absence of extratropical forcing during strong and weak MRG seasons. To identify the signature of extratropical forcing during strong and weak seasons, wind and geopotential anomalies were correlated with the MRG wave index at different pressure levels at various time lags. Figure 14 shows the lead-lag correlation coefficients representing the wind and geopotential structures of MRG waves at $300 \mathrm{hPa}$ during strong and weak seasons. (A similar structure is observed at other pressure levels as well, 

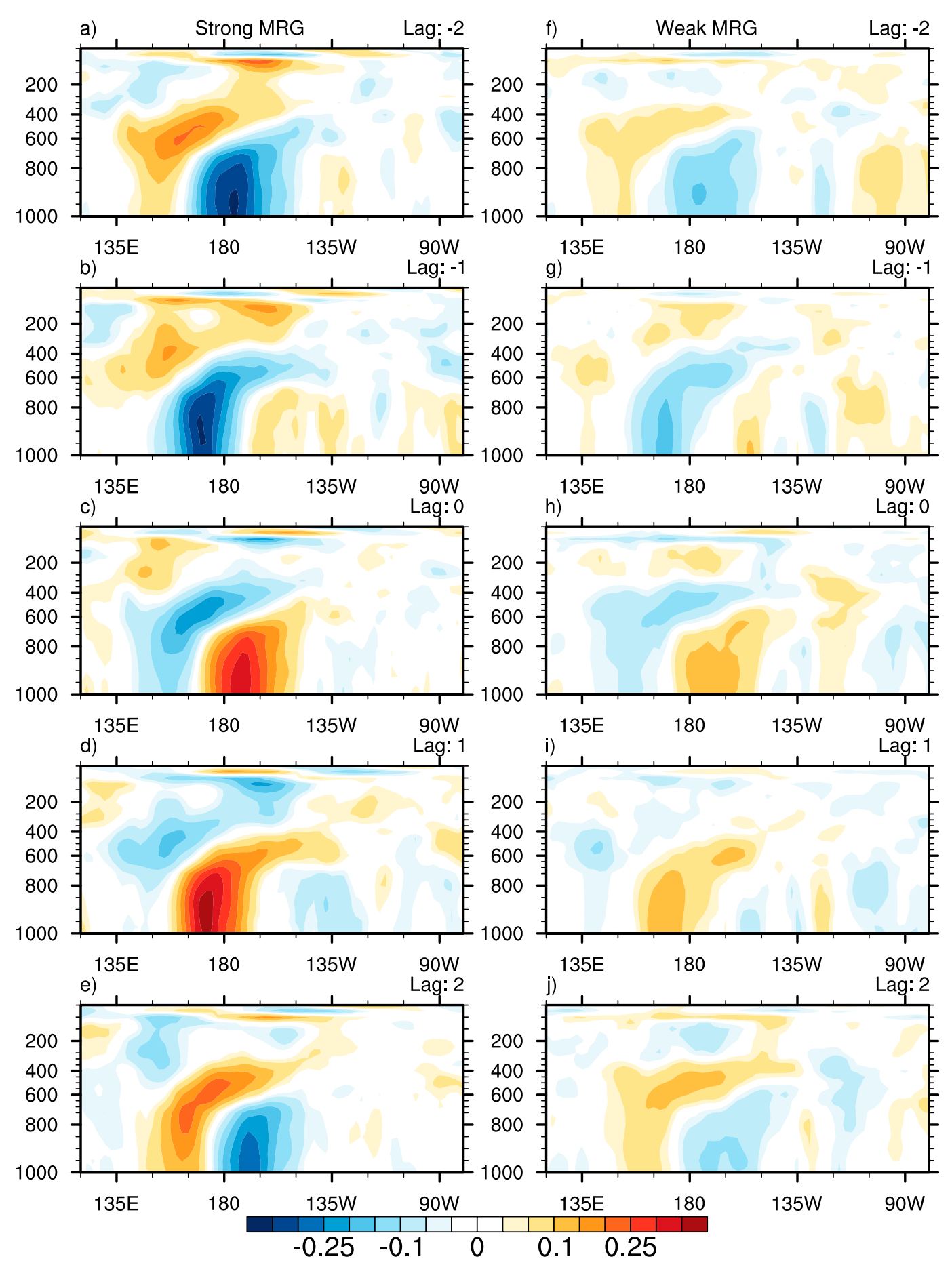

FIG. 10. Longitude-pressure structure of the MRG waves in zonal wind anomalies at different time lags for (a)-(e) strong and (f)-(j) weak MRG wave seasons at -2 to +2 day time lags. The lead-lag structure is constructed by correlating the MRG wave index with the antisymmetrically averaged zonal wind anomalies at $7.5^{\circ} \mathrm{N}$, at $1000-50 \mathrm{hPa}$ pressure levels for different time lags. A positive lag value indicates that the MRG wave index leads the wind anomalies.

but the strong-weak contrast is most evident at $300 \mathrm{hPa}$ and hence shown here.) A clear signature of extratropical wave intrusion from the Southern Hemisphere extratropics to the tropical central Pacific (MRG active region) is evident during strong MRG seasons. It is interesting to note that the extratropical waves enter the central Pacific by taking the east Indian Ocean-west Pacific route. Such extratropical wave intrusions are not observed during the weak MRG seasons, 

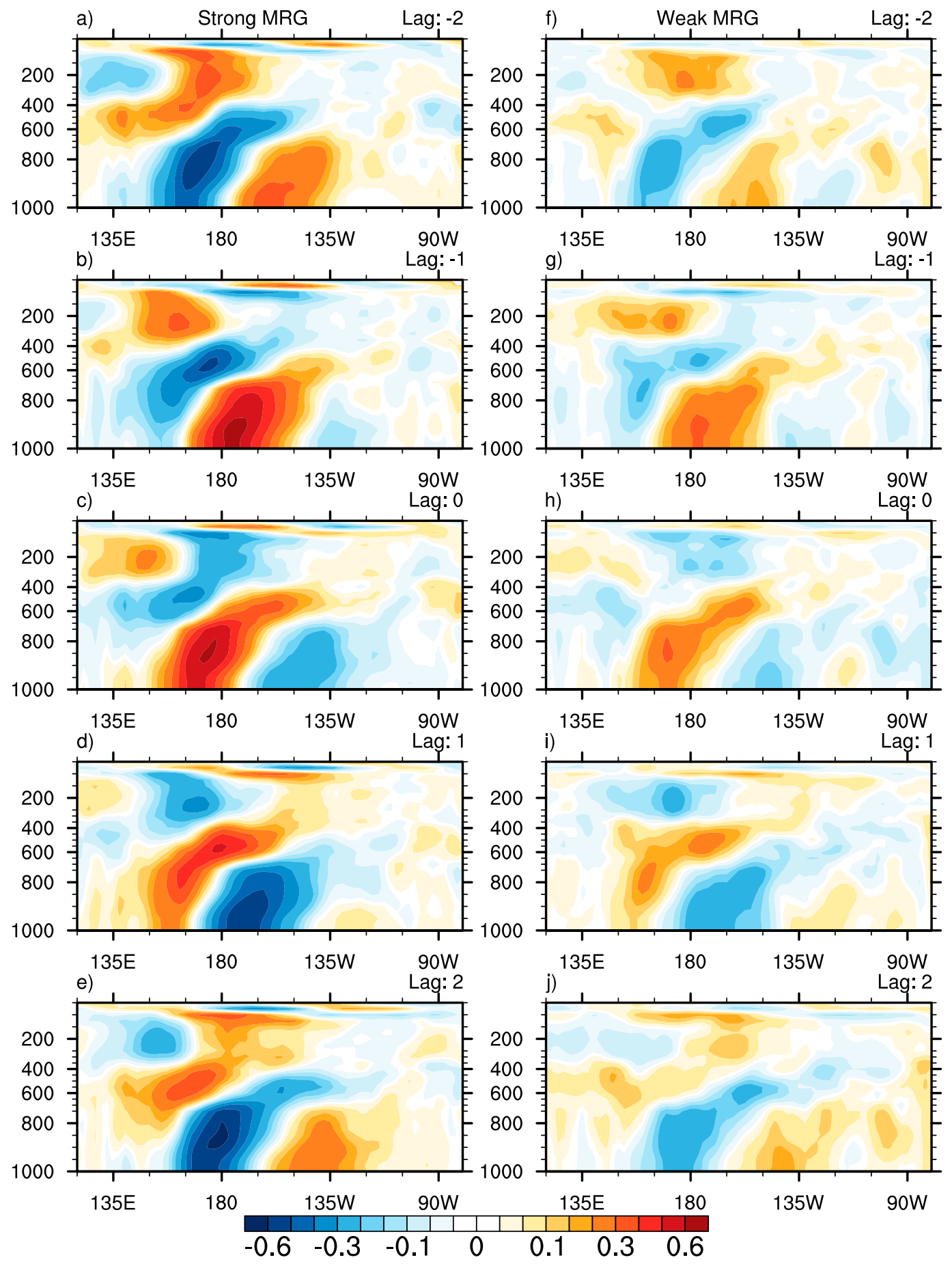

FIG. 11. Longitude-pressure structure of the MRG waves in meridional wind anomalies at different time lags for (a)-(e) strong and (f)-(j) weak MRG wave seasons at -2 to +2 day time lags. The lead-lag structure is constructed by correlating the MRG wave index with the symmetrically averaged meridional wind anomalies at the equator, at 1000-50 hPa pressure levels for different time lags. A positive lag value indicates that the MRG wave index leads the wind anomalies.

which indicates that the Southern Hemispheric extratropical wave trains might be playing a critical role in enhancing the MRG wave activity during strong MRG seasons. The observation of Southern Hemispheric extratropical wave intrusion is consistent with Fukutomi and Yasunari (2014), who explored the role of extratropical waves in exciting tropical disturbances. They found that eastward- and northeastward-propagating extratropical wave trains from the South Atlantic move toward the 

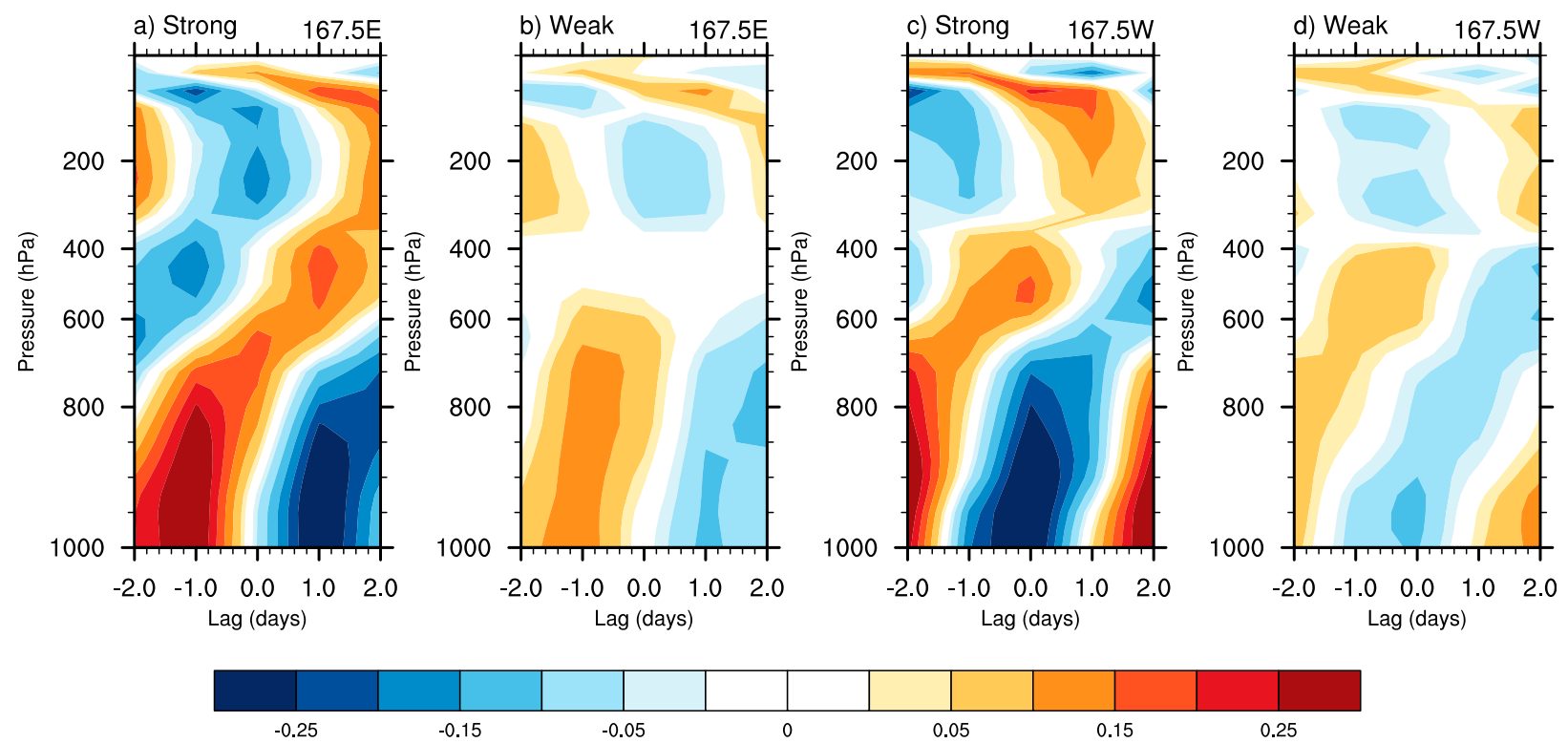

FIG. 12. (a),(b) Relative vorticity anomalies at the equator, west of the date line $\left(0^{\circ}, 167.5^{\circ} \mathrm{E}\right)$ at $1000-50 \mathrm{hPa}$ pressure levels, correlated with the MRG wave index at different time lags for strong and weak MRG wave seasons, respectively. (c), (d) As in (a) and (b), but for the relative vorticity anomalies east of the date line $\left(0^{\circ}, 167.5^{\circ} \mathrm{W}\right)$. A positive lag value indicates that the MRG wave index leads the relative vorticity anomalies.

western subtropical Indian Ocean. These findings also tend to support Itoh and Ghil's (1988) hypothesis that extratropical wave intrusions amplify the MRG waves and prefer a lower wavelength. Since the MRG waves are considered instrumental in initiating tropical disturbances like tropical depressions, tropical cyclones, and the MJO, the role of initiation/enhancement of MRG waves by extratropical wave intrusions need to be examined in detail.

\section{Summary and conclusions}

We have examined the three-dimensional structure, horizontal and vertical propagation characteristics, and convection-circulation coupling of convectively coupled westward-propagating mixed Rossby-gravity (MRG) waves and its relationship with largescale factors such as seasonal mean background state and extratropical wave intrusions, by classifying the MRG waves based on their amplitude using OLR and ERA-Interim data from 1979 to 2019. The convectively coupled MRG wave signals in convection and circulation and their spatial and temporal evolution are obtained using EOF and linear correlation analyses. Based on the climatological distribution of variances in the wavenumber-frequency domain, MRG waves in convection were isolated as disturbances with wavenumbers falling between -10 and -2 and periods between 3 and 6 days, and within an equivalent depth range from 10 to $100 \mathrm{~m}$ (Fig. 1). The principal component corresponding to the second dominant EOF mode of the wavenumber-frequency filtered OLR data was defined as the MRG wave index. The physical robustness of the method was verified by examining the horizontal structures associated with the MRG waves in convective
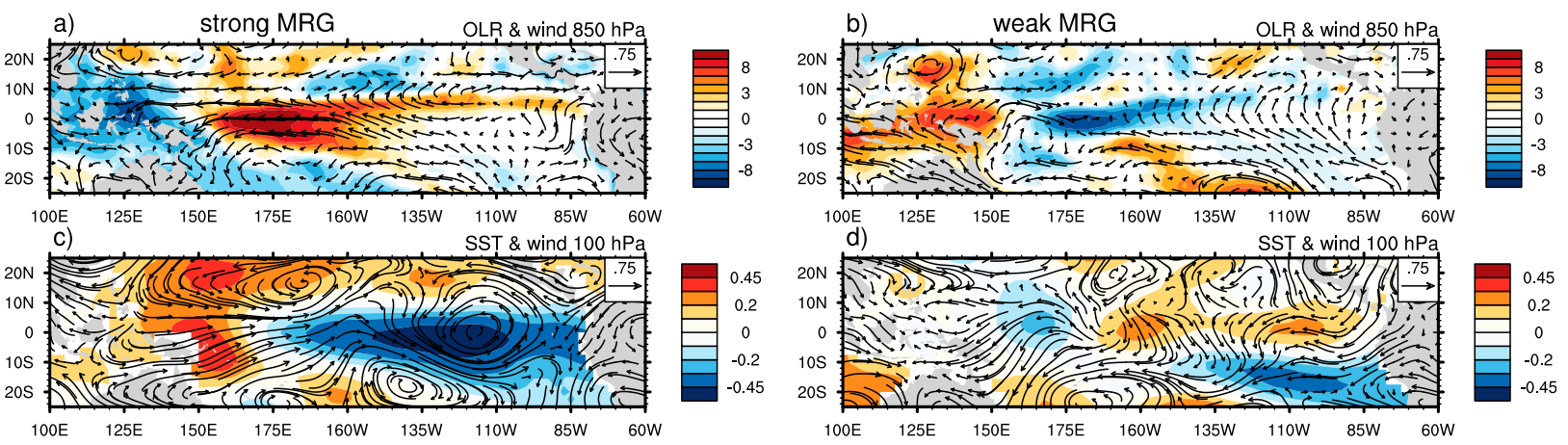

FIG. 13. (a),(b) Composite seasonal mean (August-November) OLR $\left(\mathrm{W} \mathrm{m}^{-2}\right.$ ) and $850 \mathrm{hPa}$ wind anomalies $\left(\mathrm{m} \mathrm{s}^{-1}\right)$ for strong and weak MRG wave seasons, respectively. (c),(d) Composite seasonal mean SST $\left({ }^{\circ} \mathrm{C}\right)$, and $100 \mathrm{hPa}$ wind anomalies $\left(\mathrm{m} \mathrm{s}^{-1}\right)$ for strong and weak MRG wave seasons, respectively. 

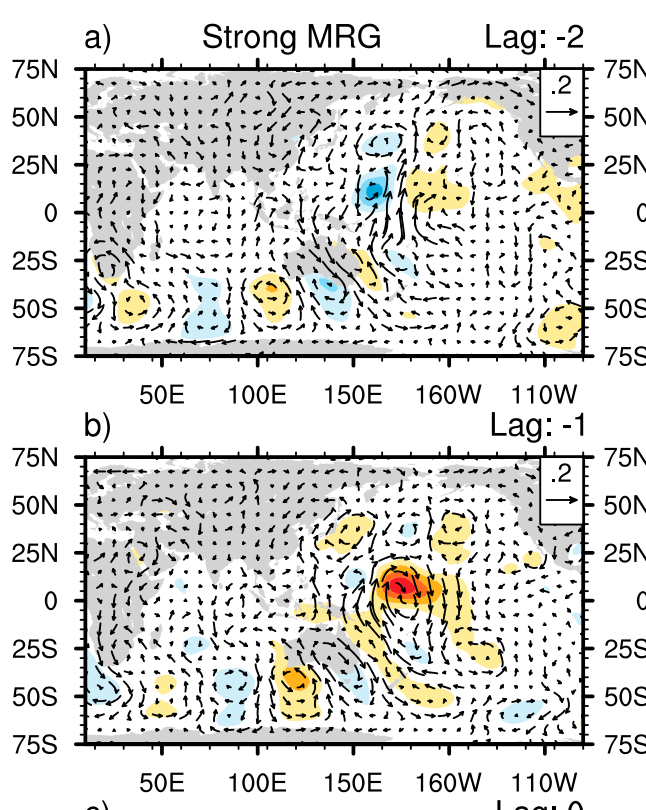

C) Lag: 0

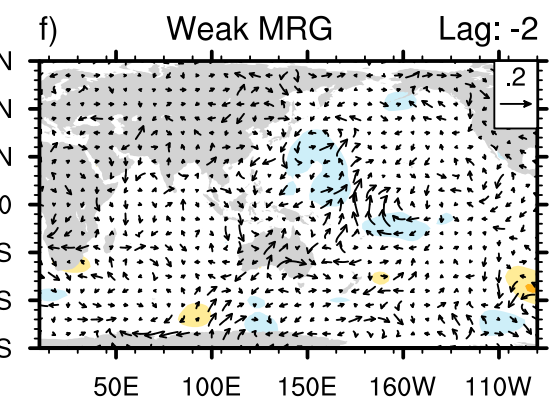

g)
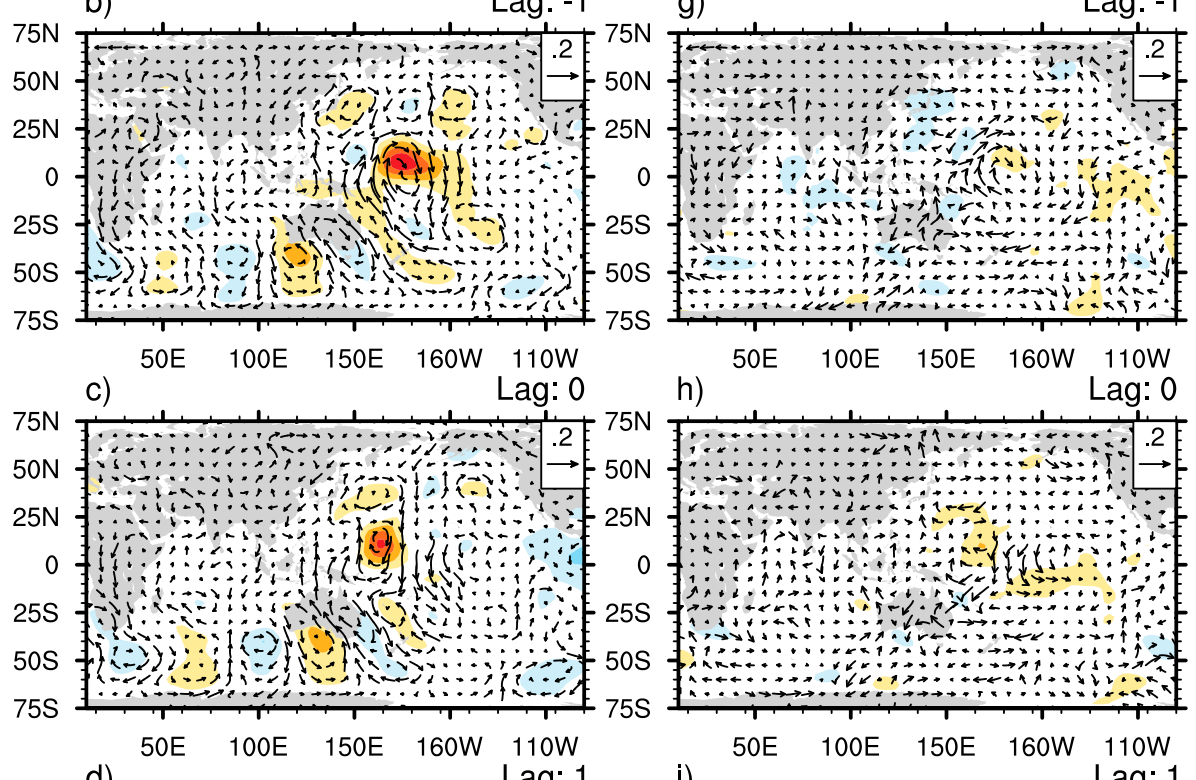

h)
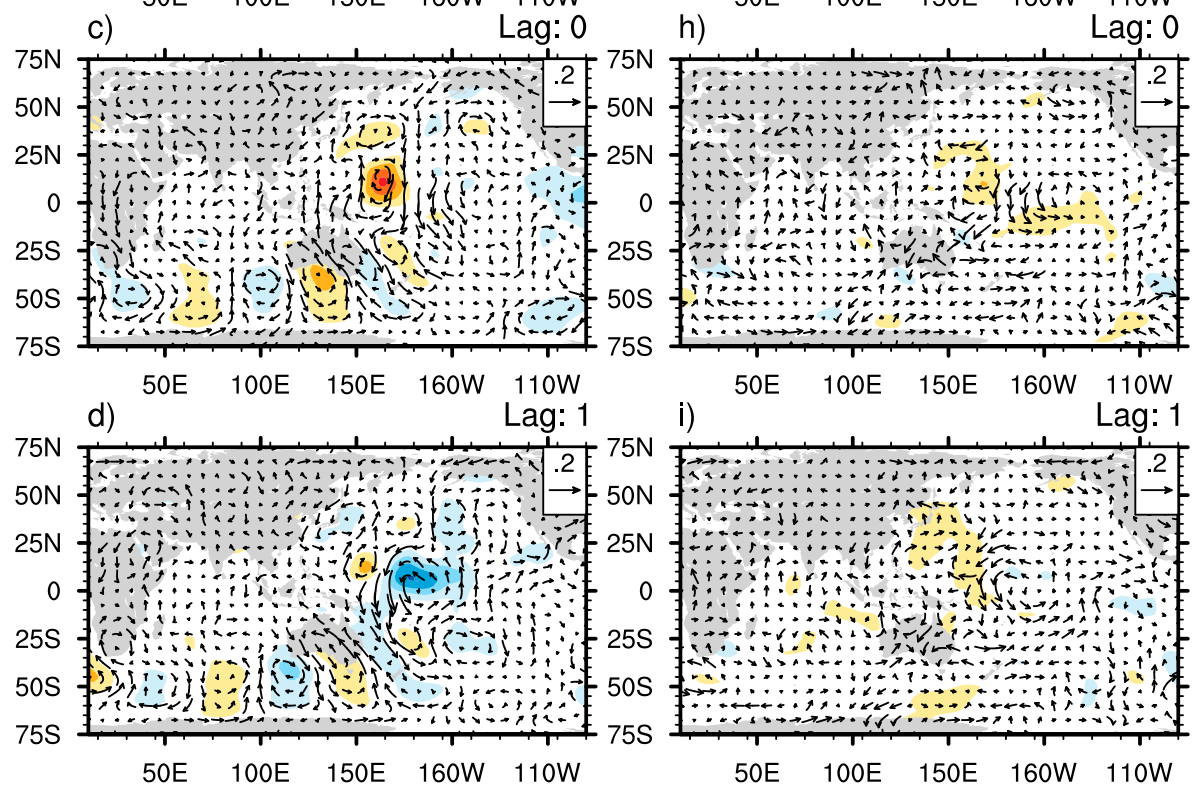

e) Lag: 2

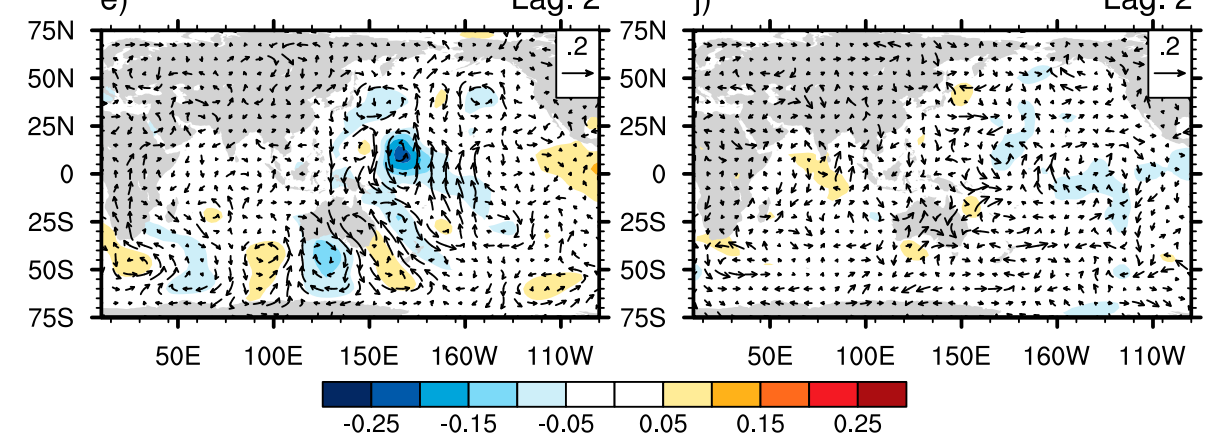

FIG. 14. Spatial correlation of the geopotential (shading) and wind (vectors) anomalies at $300 \mathrm{hPa}$ with the MRG wave index from 2-day lag to 2-day lead times during (a)-(e) strong MRG wave seasons and (f)-(j) weak MRG wave seasons. A positive lag value indicates that the MRG wave index leads the geopotential and wind anomalies. 
and circulation, derived by correlating unfiltered OLR and wind anomalies with the MRG wave index (Fig. 3). Consistent with previous studies, the MRG waves were found to be more active over the central and western Pacific (Hendon and Liebmann 1991; Takayabu and Nitta 1993; Wheeler and Kiladis 1999; Kiladis et al. 2016). Monthly distribution of MRG wave activity, identified using the MRG wave index, was found to exhibit a strong seasonality, with approximately $50 \%$ of the MRG wave activity occurring during the August-November months (late boreal summer and fall) (Fig. 4a). Hence, we selected this period as the MRG wave season and further examined the characteristics of the convectively coupled MRG waves focusing on this season. Five strong and five weak MRG wave seasons were identified during 1979-2019, based on the amplitude of MRG wave activity during the August to November months (Fig. 4b, Table 1). While the classification of MRG wave seasons was based only on amplitude, composite analysis for strong and weak MRG wave seasons, brought out considerable differences in the location of maximum amplitude and strength of convection-circulation coupling (Figs. 5 and 6).

The horizontal structure and time evolution of the convectively coupled MRG waves during strong and weak MRG wave seasons were examined by correlating the unfiltered OLR and wind anomalies against the MRG wave index at different time lags (Figs. 7 and 8). The MRG waves propagate with different phase speed during strong and weak seasons (Fig. 9). It also appears that the MRG wave structure in circulation have a larger zonal scale during strong seasons (Figs. 7 and 8), both in the lower and upper troposphere. Possibly, the underlying dynamical processes behind scale selection and convection-circulation coupling might be different during strong and weak seasons. Vertical structure and propagation characteristics of the MRG waves for strong and weak seasons were examined by correlating MRG wave index with wind anomalies at different pressure levels at different time lags. It was observed that the MRG waves exhibit a west-east vertical tilt in the troposphere and an east-west-oriented vertical tilt in the upper troposphere and stratosphere (Figs. 10 and 11). The weak and discontinuous vertical structure of the MRG waves and the absence of a continuous vertical propagation from the troposphere to the stratosphere during weak MRG wave seasons, implies how the strength of the convectively coupled MRG waves might be pertinent for establishing horizontal momentum transport from troposphere to stratosphere (Figs. 10-12).

The equatorial waves are known to be affected by different large-scale factors (Wang and Xie 1996; Yang and Hoskins 2016). Composite analysis of seasonal mean fields of SST, convection, and circulation anomalies in the lower and upper troposphere reveals the distinct background states during strong and weak MRG wave seasons. While a strong MRG wave season exhibits a La Niña-like mean state, a more El Niño-like mean state favors a weak MRG wave season (Fig. 13). This is in contrast to an earlier reported study (Wu et al. 2014) that showed that the MRG wave amplitude is not sensitive to the phases of ENSO. Further research would be necessary to understand how different background states could possibly modulate MRG wave activity. Extratropical wave intrusion is another large-scale factor that is known to influence equatorial wave disturbances (Mak 1969; Itoh and Ghil 1988; Magaña and Yanai 1995). Examination of the extratropical influences on MRG wave activity during strong and weak seasons reveals that Southern Hemispheric extratropical wave intrusion is one major factor that differentiates the strong and weak MRG wave seasons (Fig. 14). An eastward- and northeastward-propagating extratropical wave train is observed from the South Atlantic to the east Indian Ocean during strong MRG wave seasons. Since westerly background state permits intrusion of extratropical waves to the tropics, the tropical background state and extratropical wave intrusions might be working together to favor strong MRG wave activity. These observations warrant further analysis to understand the underlying physical mechanisms behind the role of background states and the interactions between extratropical wave forcing and the MRG waves.

Acknowledgments. SE acknowledges SERB-DST, Government of India, for the Ramanujan Fellowship. NJM acknowledges an early career research grant from SERB-DST, Government of India. We thank the anonymous reviewers for constructive comments and suggestions that have helped improve the manuscript significantly.

\section{REFERENCES}

Au-Yeung, A. Y. M., and C.-Y. Tam, 2018: Dispersion characteristics associated with boreal summer westward-travelling mixed Rossby-gravity wave-like disturbances. J. Atmos. Sci., 75, 513533, https://doi.org/10.1175/JAS-D-16-0245.1.

Chen, G., and R. Huang, 2009: Interannual variation of the mixed Rossby-gravity waves and their impact on tropical cyclogenesis over the western North Pacific. J. Climate, 22, 535-549, https://doi.org/10.1175/2008JCLI2221.1.

Dee, D. P., and Coauthors, 2011: The ERA-Interim reanalysis: Configuration and performance of the data assimilation system. Quart. J. Roy. Meteor. Soc., 137, 553-597, https://doi.org/ 10.1002/qj.828.

Dickinson, M., and J. Molinari, 2002: Mixed Rossby-gravity waves and western Pacific tropical cyclogenesis. Part I: Synoptic evolution. J. Atmos. Sci., 59, 2183-2196, https://doi.org/ 10.1175/1520-0469(2002)059<2183:MRGWAW>2.0.CO;2.

Dunkerton, T. J., 1993: Observation of 3-6-day meridional wind oscillations over the tropical Pacific, 1973-1992: Vertical structure and interannual variability. J. Atmos. Sci., 50, 3292-3307, https://doi.org/ 10.1175/1520-0469(1993)050<3292:OODMWO > 2.0.CO;2.

_ , and M. Baldwin, 1995: Observation of 3-6-day meridional wind oscillations over the tropical Pacific, 1973-1992: Horizontal structure and propagation. J. Atmos. Sci., 52, 1585-1601, https://doi.org/ 10.1175/1520-0469(1995)052<1585:OODMWO>2.0.CO;2.

Feng, T., X.-Q. Yang, W. Zhou, R. Huang, L. Wu, and D. Yang, 2016: Synoptic-scale waves in sheared background flow over the western North Pacific. J. Atmos. Sci., 73, 4583-4603, https://doi.org/10.1175/JAS-D-16-0064.1.

Fukutomi, Y., and T. Yasunari, 2014: Extratropical forcing of tropical wave disturbances along the Indian Ocean ITCZ. J. Geophys. Res. Atmos., 119, 1154-1171, https://doi.org/ 10.1002/2013JD020696.

Hayashi, Y., and D. G. Golder, 1978: The generation of equatorial transient waves: Control experiments with a GFDL general circulation model. J. Atmos. Sci., 35, 2068-2082, https://doi.org/10.1175/ 1520-0469(1978)035<2068:TGOETP>2.0.CO;2. 
Hendon, H. H., and B. Liebmann, 1991: The structure and annual variation of antisymmetric fluctuations of tropical convection and their association with Rossby-gravity waves. J. Atmos. Sci., 48, 2127-2140, https://doi.org/10.1175/1520-0469(1991) 048<2127:TSAAVO $>2.0$. CO 2 .

— , and M. C. Wheeler, 2008: Some space-time spectral analysis of tropical convection and planetary-scale waves. J. Atmos. Sci., 65, 2936-2948, https://doi.org/10.1175/2008JAS2675.1.

Holton, J. R., and R. S. Lindzen, 1972: An updated theory for the quasi-biennial cycle of the tropical stratosphere. J. Atmos. Sci., 29, 1076-1080, https://doi.org/10.1175/1520-0469(1972)029<1076: AUTFTQ $>2.0 . \mathrm{CO} ; 2$.

Itoh, H., and M. Ghil, 1988: The generation mechanism of mixed Rossby-gravity waves in the equatorial troposphere. J. Atmos. Sci., 45, 585-604, https://doi.org/10.1175/1520-0469(1988) 045<0585:TGMOMR > 2.0.CO;2.

Kiladis, G. N., M. C. Wheeler, P. T. Haertel, K. H. Straub, and P. E. Roundy, 2009: Convectively coupled equatorial waves. Rev. Geophys., 47, RG2003, https://doi.org/10.1029/2008RG000266.

—, J. Dias, and M. Gehne, 2016: The relationship between equatorial mixed Rossby-gravity and eastward inertio-gravity waves. Part I. J. Atmos. Sci., 73, 2123-2145, https://doi.org/ 10.1175/JAS-D-15-0230.1.

Lau, K.-H., and N.-C. Lau, 1990: Observed structure and propagation characteristics of tropical summertime synoptic scale disturbances. Mon. Wea. Rev., 118, 1888-1913, https://doi.org/ 10.1175/1520-0493(1990)118<1888:OSAPCO >2.0.CO;2.

Liebmann, B., and C. A. Smith, 1996: Description of a complete (interpolated) outgoing longwave radiation dataset. Bull. Amer. Meteor. Soc., 77, 1275-1277, https://doi.org/10.1175/ 1520-0477-77.6.1274.

Lin, P., I. Held, and Y. Ming, 2019: The early development of the 2015/16 quasi-biennial disruption. J. Atmos. Sci., 76, 821-836, https://doi.org/10.1175/JAS-D-18-0292.1.

Magaña, V., and M. Yanai, 1995: Mixed Rossby-gravity waves triggered by lateral forcing. J. Atmos. Sci., 52, 1473-1486, https://doi.org/ 10.1175/1520-0469(1995)052<1473:MRWTBL > 2.0.CO;2.

Mak, M.-K., 1969: Laterally driven stochastic motions in the tropics. J. Atmos. Sci., 26, 41-64, https://doi.org/10.1175/15200469(1969)026<0041:LDSMIT >2.0.CO;2.

Maruyama, T., and M. Yanai, 1967: Evidence of large-scale wave disturbances in the equatorial lower stratosphere. J. Meteor. Soc. Japan, 45, 196-199, https://doi.org/10.2151/jmsj1965.45.2_ 196.

Matsuno, T., 1966: Quasi-geostrophic motions in the equatorial area. J. Meteor. Soc. Japan, 44, 25-43, https://doi.org/10.2151/ jmsj1965.44.1_25.

North, G. R., T. L. Bell, R. F. Cahalan, and F. J. Moeng, 1982: Sampling errors in the estimation of empirical orthogonal functions. Mon. Wea. Rev., 110, 699-706, https://doi.org/ 10.1175/1520-0493(1982)110<0699:SEITEO > 2.0.CO;2.

Plumb, R. A., 1977: The interaction of two internal waves with the mean flow: Implications for the theory of the quasi-biennial oscillation. J. Atmos. Sci., 34, 1847-1858, https://doi.org/ 10.1175/1520-0469(1977)034<1847:TIOTIW>2.0.CO;2.

Reynolds, R. W., N. A. Rayner, T. M. Smith, D. C. Stokes, and W. Wang, 2002: An improved in situ and satellite SST analysis for climate. J. Climate, 15, 1609-1625, https://doi.org/10.1175/ 1520-0442(2002)015<1609:AIISAS > 2.0.CO;2.

Roundy, P. E., 2015: On the interpretation of EOF analysis of ENSO, atmospheric Kelvin waves, and the MJO. J. Climate, 28, 1148-1165, https://doi.org/10.1175/JCLI-D-14-00398.1.
—, and W. M. Frank, 2004: A climatology of waves in the equatorial region. J. Atmos. Sci., 61, 2105-2132, https:// doi.org/10.1175/1520-0469(2004)061<2105: ACOWIT $>2.0 . \mathrm{CO} ; 2$

Sobel, A. H., and C. S. Bretherton, 1999: Development of synopticscale disturbances over the summertime tropical northwest Pacific. J. Atmos. Sci., 56, 3106-3127, https://doi.org/10.1175/ 1520-0469(1999)056<3106:DOSSDO > 2.0.CO;2.

Takasuka, D., M. Satoh, T. Miyakawa, and H. Miura, 2018: Initiation processes of the tropical intraseasonal variability simulated in an aqua-planet experiment: What is the intrinsic mechanism for MJO onset? J. Adv. Model. Earth Syst., 10, 1047-1073, https://doi.org/10.1002/2017MS001243.

- — - and S. Yokoi, 2019: Observational evidence of mixed Rossby-gravity waves a driving force for the MJO convective initiation and propagation. Geophys. Res. Lett., 46, 5546-5555, https://doi.org/10.1029/2019GL083108.

Takayabu, Y. N., 1994: Large-scale cloud disturbances associated with equatorial waves. J. Meteor. Soc. Japan, 72, 433-449, https://doi.org/10.2151/jmsj1965.72.3_433.

_— and T. Nitta, 1993: 3-5 day-period disturbances coupled with convection over the tropical Pacific Ocean. J. Meteor. Soc. Japan, 71, 221-246, https://doi.org/10.2151/jmsj1965.71.2_221.

__, G. N. Kiladis, and V. Magaña, 2016: Michio Yanai and tropical waves. Multiscale Convection-Coupled Systems in the Tropics, Meteor. Monogr., No. 56, Amer. Meteor. Soc., https:// doi.org/10.1175/AMSMONOGRAPHS-D-15-0019.1.

Wang, B., 2006: Theory. Intraseasonal Variability in the AtmosphereOcean Climate System, W. K.-M. Lau and D. E. Waliser, Eds., Springer Praxis, 307-360.

cally sheared zonal flow. Part I: Stable waves. J. Atmos. Sci., 53, 449-467, https://doi.org/10.1175/1520-0469(1996) $053<0449$ :LFEWIV $>2.0$. CO 2 .

Wheeler, M., and G. N. Kiladis, 1999: Convectively coupled equatorial waves: Analysis of clouds and temperature in the wavenumber-frequency domain. J. Atmos. Sci., 56, 374-399, https://doi.org/10.1175/1520-0469(1999)056<0374: $\mathrm{CCEWAO}>2.0 . \mathrm{CO} ; 2$.

—, _ and P. J. Webster, 2000: Large-scale dynamical fields associated with convectively coupled equatorial waves. J. Atmos. Sci., 57, 613-640, https://doi.org/10.1175/15200469(2000)057<0613:LSDFAW >2.0.CO;2.

Wu, L., Z. Wen, T. Li, and R. Huang, 2014: ENSO-phase dependent TD and MRG wave activity in the western North Pacific. Climate Dyn., 42, 1217-1227, https://doi.org/10.1007/s00382-013-1754-4.

Yanai, M., and T. Maruyama, 1966: Stratospheric wave disturbances propagating over the equatorial Pacific. J. Meteor. Soc. Japan, 44, 291-294, https://doi.org/10.2151/jmsj1965.44.5_291.

_- and M. Murakami, 1970: Spectrum analysis of symmetric and antisymmetric equatorial waves. J. Meteor. Soc. Japan, 48, 331-347, https://doi.org/10.2151/jmsj1965.48.4_331.

_, T. Maruyama, T. Nitta, and Y. Hayashi, 1968: Power spectra of large-scale disturbances over the tropical Pacific. J. Meteor. Soc. Japan, 46, 308-323, https://doi.org/10.2151/jmsj1965.46.4_308.

Yang, G. Y., and B. J. Hoskins, 2016: ENSO related variation of equatorial MRG and Rossby waves and forcing from higher latitudes. Quart. J. Roy. Meteor. Soc., 142, 2488-2504, https:// doi.org/10.1002/qj.2842.

Zhao, H., X. Jiang, L. Wu, and P. J. Klotzbach, 2019: Multi-scale interactions of equatorial waves associated with tropical cyclogenesis over the western North Pacific. Climate Dyn., 52, 3023-3038, https://doi.org/10.1007/s00382-018-4307-z. 